\title{
Incorporating HIV/AIDS Considerations into Vulnerability Assessments for Disaster Risk \\ Reduction
}

\author{
Gideon van Riet
}

\section{Introduction}

Sub-Saharan Africa is stricken by a generalised HIV/AIDS pandemic that will only reach its peak approximately by the year 2022 (Whiteside, 2002:313). ${ }^{1}$ As was widely debated during the recent 2001-2003 Southern African Food Security Crisis, the pandemic contributes to vulnerability in various ways (De Waal, And Whiteside, 2003; Harvey, 2004). ${ }^{2}$ However, the link between HIV/AIDS and vulnerability in Africa has not yet been explicitly addressed from the perspective of disaster risk reduction (DRR), as opposed to informing post disaster interventions. This paper offers a preliminary investigation of how survey based vulnerability assessments, might be informed by HIV/AIDS considerations, if vulnerability to the effects of natural hazards such as droughts and floods is to be effectively mitigated.

The paper briefly highlights the link between HIV/AIDS and vulnerability, the latter being a focus point of DRR. In particular it investigates in which ways HIV/AIDS contributes to the vulnerability (for the purposes of this discussion defined as the susceptibility of households to the negative effects of certain natural hazards, brought on by the interplay between various political, economic, social and environmental factors) of households. Secondly, the paper investigates the possible measurement of HIV/AIDS in general vulnerability assessments used for the purposes of DRR, by evaluating the merit of certain indicators often used to target humanitarian aid.

\section{HIV/AIDS and vulnerability}

As Drimie (2000:11) notes, HIV/AIDS affects economic growth. However its most acute impacts is felt at the level of the household. The following is a simplified discussion of the ways in which households are typically affected. Due to a lack of space an in depth discussion will not be possible. 
HIV/AIDS can imply a financial strain on a household through medical expenses, absenteeism from work, or eventually through funeral expenses. Stigmatisation due to infection can limit social linkages and networks (for example family and community members), thus limiting access to resources (Van Lierre, 2002:7; Drimie, 2002:8). In addition, the death of family members providing remittances to households can inflict a financial shock on a household, even more so if it is coupled with the care of those individuals. Extended families might also be over extended, both financially and in terms of care giving. Orphans and sick adults often move in with family members (particularly in rural areas). The burden of the care of sick adults might cause productive duties to be neglected or children to be taken out of school. In order to cover expenses, households may sell productive assets such as animals, which impairs future productivity. The death of household members can lead to a loss of productivity, as households lack sufficient labour to maintain a livelihood. In patrilineal systems in some African contexts, widows and their children might loose access to land if she refuses to marry one of her husband's brothers. Many orphans are not taken in by extended families and thus burdened with adult responsibilities, such as putting food on the table, long before they ought to be. Parents might also die before passing on essential knowledge to children, such as how to deal with a drought, or how to find edible wild fruits. In addition orphans are less likely to stay in school (often to work) and more likely to be malnourished (Barks-Ruggles, 2001:4).

\section{HIV/AIDS and Disaster Risk Reduction}

Understanding patterns of vulnerability (e.g. classes of people that are particularly vulnerable due to HIV/AIDS) would be useful for the purposes of DRR. Thus for example, knowledge about orphans could result in interventions aimed at helping these young people become productive members of society, by keeping them in school when their parents die and they cannot be taken in by family members.

Caution is however required. As researchers from the Department of Agricultural Economics at Michigan State University (Mather et al, 2004) have found, the concept "HIV/AIDS affected household" should not be seen as a homogenous category. The loss of labour that HIV/AIDS can inflict on a household, for example does not hold true for the death of each and every prime age adult (typically 15-49 or 15-59). Thus, in this case what one would seek to measure, would be a loss of labour and not the death of a prime age adult. In addition, it is essential to take into consideration issues such as household wealth and other assets (human, physical, social and natural) as different households would be 
differently equipped to deal with the effects of HIV/AIDS. Thus, a nuanced approach is required, something that a survey method of research is not conducive to.

DRR in sub-Saharan Africa is further complicated by the slim distinction between "disaster" and "normal" conditions in much of the region. It might well be argued that much of the region is locked in a protracted disaster. It seems natural hazards only affect the extent of the crisis. Thus, reducing vulnerability would necessarily also be accompanied by actions that are typical characteristics of emergency responses, for example providing food aid. As an example the World Food Programme (2006) reports that crop failures in southern Africa have yet again led to widespread food insecurity in the region. However, interventions by aid agencies have been ongoing since 2002.

\section{Measuring HIV/AIDS}

A typical quantitative vulnerability assessment takes measurements at the household level. However, as Drinkwater (2005:37) indicates, this might not be the best possible unit of analysis when studying livelihoods in Africa, due to the strong links that often exist between households. An HIV/AIDS affected household might not have sufficient labour to ensure adequate crop production for its own consumption, but it might have links with neighbours who have excess labour. These and other linkages between households such as remittances might, be inquired into by way of direct questions, though the full extent and significance of such linkages might never be understood.

The measurement of the effects of HIV/AIDS on vulnerability is further complicated by the difficulty of measuring HIV/AIDS related deaths and HIV/AIDS affected households. Proxy indicators (such as the presence of chronically ill adults and orphans), are often used by Non-Governmental Organisations (NGOs) when targeting food aid. These indicators pose particular problems regarding validity (Harvey, 2004:28; Swaziland Vulnerability Assessment Committee, 2004:21). In other words: does the indicator in fact measure what it's supposed to measure? However, when one is in fact measuring vulnerability (and not necessarily the effects of HIV/AIDS) many of these concerns might not be that constricting. Thus, for a vulnerability assessment to be informed by knowledge of HIV/AIDS, it does not necessarily imply that HIV/AIDS affected households always need to be isolated. Save the Children (2004:19) outlines the various proxy indicators that have been used in the past. These gauge HIV/AIDS infected and affected households. 
Chronically ill adults (typically 15-49): Households with chronically ill members were targeted to receive food aid by NGOs in the recent (2001-2003) food security crisis in southern Africa. This category was defined as: being ill for three months or more. This is arguably the one indicator where it would be useful to know the cause of the condition being measured. It would directly affect the type of intervention (e.g. drugs or supplementary feeding). There is, however, no way of knowing for certain that the illness is necessarily a manifestation of AIDS. In a study in Rwanda it was attempted to remedy this deficiency in the measuring instrument by correlating chronic illness with four common symptoms of AIDS (fever, chronic diarrhoea, skin rash and weight loss) (Donovan and Mather, 2004:14). It was suggested that a chronically ill person had to have had at least three of these symptoms to be considered sick with AIDS. However, the research found that most cases of chronically ill adults or adult deaths only correlated with two of these symptoms (Donovan and Mather, 2004:14). Clearly more research is needed in order to better measure illness with AIDS. In addition, chronic illness has to be clearly defined, so that there is no confusion for respondents. For example, being ill for three months over the last year and being ill for three consecutive months is very different (Save the Children, 2004:19).

Recent death of an adult in the household: With regards to this indicator it is especially important to clearly define "recent". In addition "following chronic illness" should be added, in order to limit inclusion errors. However, what is required is to understand to what extent the death of that adult has increased vulnerability. This might be done through supplementary questions relating to the loss of income that the death of a specific adult brought on.

Elderly and child headed households: An elderly headed household could have multiple causes. All elderly and child headed households may not be HIV/AIDS affected; however, for the purposes of disaster risk reduction, the fact that they are elderly and child headed households could contribute to vulnerability. Households with few or no prime age adults may have impaired livelihoods and a lack of capabilities in terms of resources and knowledge to deal with a natural hazard, for example in the absence of social grants and the inability of the elderly to significantly contribute income generating activities. 
High dependency ratios: Similarly, households with high dependency ratios (that is, households with many dependents on few income earning household members) may not necessarily be HIV/AIDS affected, though knowledge about such households in itself would be useful for the purposes of DRR. However, as with all proxy indicators it makes sense to take into consideration measures of wealth, such as overall or per capita income when targeting interventions.

Female/Widow headed households: This indicator is not that useful at the household level as there could be many causes (Save the Children 2004:19).

Presence of malnourished adult in the household: In light of persistent food insecurity especially in in the southern African region, this indicator is clearly not a valid measure of HIV/AIDS infection. In addition, Save the Children notes that there are no generally agreed measures for malnourishment. However, in principle it does make sense to incorporate food security measures in vulnerability assessments, as this represents very immediate needs. However, various authors (Drimie, 2002; Barnett and Whiteside 2002; Loevinsohn and Gillespie, 2003) note the impact of food insecurity on HIV/AIDS, for example in facilitating the spread of HIV, through transactional sex or hastening the progression from HIV to AIDS, by further undermining the immune systems of HIV positive individuals. Thus, in this regard addressing food insecurity could be seen as a way of limiting future vulnerability.

Presence of a chronically ill child (aged 0-5 years): On its own this indicator does not tell whether the mother is deceased, ill or neither. It is merely a potential proxy of HIV/AIDS in the mother. More information regarding the vulnerability of the household would have to be acquired, possibly in combination with a chronically ill mother.

Labour poor households: This measurement is an aggregate between various other indicators, for example child headed with chronic illness. This measure would have very specific applications, and is possibly not fit for a general vulnerability assessment.

It should be noted that a typical vulnerability assessment survey, is a snapshot of a given timeframe of a specific community. Vulnerability can, however, be seen as a process, one that could accelerate rapidly for AIDS affected households if key productive household members fall ill. 
Thus, assessments might have to be done on an ongoing basis, making it an expensive exercise. In addition, once certain trends in a community have been identified, an effective, nuanced approach might require subsequent phases of targeting in order to isolate and effectively address household/household member specific needs. Such a complex process might be unaffordable, even with large scale donor funding.

A large proportion of the discussion above implicitly relates to rural livelihoods. Most of the literature on the effects of HIV/AIDS on livelihoods in Africa specifically focuses on rural livelihoods. Less well understood is the effect of the pandemic in urban settings. There is definitely a need for more empirical studies in this regard to help build an evidence base.

Finally, what this paper proposes is not that vulnerability assessments be dominated by HIV/AIDS. There exists a fierce debate regarding the extent of the impact of HIV/AIDS on vulnerability and there are arguably no satisfactory answers yet. However, given the protracted nature of the HIV/AIDS crisis and the fact that it does produce a very specific brand of vulnerability, affecting new categories of people, it ought to be a consideration.

\section{Conclusions}

This paper preliminarily investigates the introduction of knowledge of HIV/AIDS in vulnerability assessments for the purposes of DRR. The above discussion suggests that many of the constraints of proxy indicators relating to issues of validity can be avoided when used in general vulnerability assessments in "normal times" (that is, to mitigate the possible impact of natural hazards and not in response to disasters). The type of vulnerability often produced by HIV/AIDS is an important consideration in this regard and not necessarily the presence of HIV/AIDS itself. More research is however required to reliably measure illness with AIDS. In this regard proxy indicators remain an unsatisfactory way of measuring HIV/AIDS.

The incorporation of HIV/AIDS considerations into vulnerability assessments is a necessary exercise, as it creates new categories of vulnerable people. Understanding the extent of this type of vulnerability in a specific area and addressing it in "normal" times could help lessen the impacts of natural hazards on communities. Financial considerations might however severely limit the extent to which what this paper proposes, can be implemented. 


\begin{abstract}
${ }^{1}$ A generalized epidemic is one where $1 \%$ of women tested at antenatal clinics, tests positive. Under these circumstances infection is spread predominantly through heterosexual intercourse.

${ }^{2}$ The food security crisis was characterized by a lack of availability and access to food for large proportions of the populations in six countries: Lesotho, Malawi, Mozambique, Swaziland, Zambia and Zimbabwe. It is generally accepted that the crisis was triggered by extreme weather conditions, but that there were deeper underlying circumstances that made people vulnerable to the negative effects of these weather conditions.
\end{abstract}




\section{References}

BARKS-RUGGLES, 2001. Meeting the global challenge of HIV/AIDS. The Brookings Institute, Policy brief number 75, April. [Web:]

http://www.brook.edu/comm/policybriefs/pb75.pdf [Date of access: 13 Sept 2006].

BARNETT, T. AND WHITESIDE, A. 2002. Poverty and HIV/AIDS: Impact, Coping and Mitigation Strategies. (In Cornia, G. A., ed. AIDS, Public Policy and Child Wellbeing.) [Web:]

http://www.unicef-icdc.org/research/ESP/aids/chapter11.pdf [Date of access: 13 Jul 2005].

DRIMIE, S. 2002. The Impact of HIV/AIDS on Rural Household and Land Issues in Southern and Eastern Africa. Background Paper prepared for the Food and Agricultural Organisation, Sub-Regional Office for Southern and Eastern Africa. August 2002. [Web:] http://www.oxfam.org.uk/what we do/issues/livelihoods/landrights/downloads/hivbackg.pdf [Date of access: 24 Jul 2005].

DRINKWATER, M. 2005. HIV/AIDS and Agriculture in southern Africa: What difference does it make? IDS Bulletin, Volume 36, Number 2. June 2005.

HARVEY, P. 2004. HIV/AIDS and Humanitarian Action. HPG Report 16. [Web:]

http://www.odi.org.uk/hpg/papers/hpgreport16.pdf [Date of Access: 25 Oct 2006].

LOEVINSOHN, M. AND GILLESPIE, S. 2003. HIV/AIDS, Food Security and Livelihoods: Understanding and Responding. RENEWAL Working Paper no. 2. [Web:] http://www.ifpri.org/themes/hiv/hivpubs.asp [Date of access: 11 April 2005].

MATHER, D., DONOVAN, C., JAYNE, T.S., WEBER, M. CHAPOTO, A., MAZHANGARA, E., BAILEY, L., YOO, K., YAMATO, T AND MGHENYI, E. 2004. A Cross-country analysis of household responses to adult mortality in rural sub-Saharan Africa: Implications for HIV/AIDS mitigation and rural development policies. Department of Agricultural Economics, Michigan State University. [Web:]

http://www.aec.msu.edu/agecon/fs2/papers/IDWP82.pdf [Date of Access: 6 Sept 2006]. 
SAVE THE CHILDREN, 2004. Food Security, Livelihoods and HIV/AIDS: A guide to the linkages, measures and programming implications. [Web:]

http://www.reliefweb.int/library/documents/2004/scf-souafr31aug.pdf\#search=\%22Food\%20Security\%2C\%20Livelihoods\%20and\%20HIV\%2FAIDS\% 3A\%20A\%20guide\%20to\%20the\%20linkages\%2C\%20Measures\%20and\%20programming \%20implications\%22

[Date of access: 6 Sept 2006].

SWAZILAND VULNERABILITY ASSESSMENT COMMITTEE, 2004. A Study To Determine The Links Between HIV/AIDS, Current Demographic Status And Livelihoods In Rural Swaziland. [Web:] http://www.sarpn.org.za/documents/d0000784/P904-Swaziland VAC April2004.pdf. [Date of Access: 25 Oct. 2005]

VAN LIERRE, M. J. 2002. HIV/AIDS and Food Security in Sub-Saharan Africa Paper presented at the $7^{\text {th }}$ Annual ECOWAS Nutrition Forum Banjul, the Gambia, 2-6 September. [Web:]

http://www.sahims.net/doclibrary/Documents/briefcases/hivaids/estherl AIDSfoodsecurityp aperECOWAS.pdf [Date of access: 13 Sept 2006].

WHITESIDE, A. 2002. Poverty and HIV/AIDS in Africa, in Third World Quarterly, Volume 23, Number 2, pp 313-332.

WORLD FOOD PROGRAMME, 2006. WFP launches massive appeal. [Web:] http://www.wfp.org/newsroom/in depth/Africa/southern africa020705.asp?section=2\&sub section=2 [Date of access: 1 November 2006]. 